Acta Technologica Agriculturae 2

Nitra, Slovaca Universitas Agriculturae Nitriae, 2015, pp. 49-53

\title{
VERIFICATION OF CONDITIONS FOR USE OF COMBUSTION PRODUCTS' HEAT
}

\author{
Viera KAŽIMÍROVÁ*1, Vladimír ČEREŠŇN² \\ 'Slovak University of Agriculture in Nitra, Slovak Republic \\ ${ }^{2}$ Eustream, a.s., Slovak Republic
}

\begin{abstract}
Presented contribution deals with the verification of conditions for use of combustion products' heat, generated by combustion of wood in a fireplace used in a household. It is necessary to know the temperature behaviour of the fireplace to determine the adequacy of the technical solution for using combustion products' heat. The combustion products' temperature at the upper part of the chimney is $80-120^{\circ} \mathrm{C}$. The dew point value was established to be below $51^{\circ} \mathrm{C}$. The average observed value of combustion product velocity is $1.6 \mathrm{~m} \mathrm{~s}^{-1}$. The volume flow rate of combustion products is $12 \mathrm{~m}^{3} \mathrm{~h}^{-1}$. Measured values allow for effective solution of the use of combustion products' heat.
\end{abstract}

Keywords: temperature, fireplace, dew point, chimney

In our climate zone, it is estimated that biomass will amount to $6-12 \%$ of energy sources (Janíček et al., 2007). In Slovakia, it is mainly a solid form of biomass for heating in urban heating plants. In recent years, the biomass-based clean fuel mainly in the form of pellets and briquettes has become very popular (Vitázek et al., 2014). Currently, it is necessary to pay attention to energy consumption and to utilisation of waste heat, not only in industry and agriculture sector but also in homes where fireplace is used often as an alternative energy source.

Fireplaces are used mostly for heating of individual rooms. Wood combustion can take place in several ways, with varying combustion efficiency. In a hot-air fireplace, heating of air takes place by air flowing past the firebox and being propelled by a fan into the rooms. The efficiency can vary, depending on the type of the core, from $50 \%$ to $70 \%$ (Dufka, 1997).

In case of fireplace combustion, the utilisation of waste heat consists of taking heat from combustion products in the chimney and returning it into the heated space by means of recuperation. Energy back flow, which reduces energy consumption for heating, is provided by a heat exchanger, either flue gas - air or flue gas - water.

Known temperatures in the combustion system and exhaust system are the basis for the solution design for utilisation of energy that would otherwise escape into the atmosphere.

\section{Material and methods}

The aim of the analysis is to determine the velocity, flow and temperature of combustion products and the dew point. These parameters have to be measured at several points of the chimney and flue duct. Air temperature and humidity in room are also measured. These parameters are variable in time; therefore, measurements were carried out over a 20 hour period in a single-family house, which uses central heating in combination with a fireplace.

The upper section of the chimney is the most appropriate for recording combustion products' heat. Temperature conditions were therefore determined in this part of the chimney.

\section{Temperature measurement}

A thermocouple is used for measurements of temperature. The thermocouple converts heat into electricity (voltage) at the point of connection of two metals. Voltage is processed using measuring equipment and then converted to the value of temperature.

Temperature measurement is performed using Almemo 2690-8A (Ahlborn Mess- und Regelungstechnik $\mathrm{GmbH}_{\text {, }}$ Germany) with a NiCr-Ni chip with the measurement range from $-200{ }^{\circ} \mathrm{C}$ to $1370{ }^{\circ} \mathrm{C}$.

Values of temperature of combustion products in the combustion chamber and chimney are measured in points shown in Figure 1.

\section{Humidity measurement}

The method of humidity measurement is based on the change of electric capacity between the electrodes of the capacitor. Values of capacity are converted to the appropriate variable. The capacitive probe FHA646-E1 (Ahlborn Mess- und Regelungstechnik GmbH, Germany) is used for humidity measurement.

The temperature of dew point in room is calculated using values of temperature, humidity and pressure. 


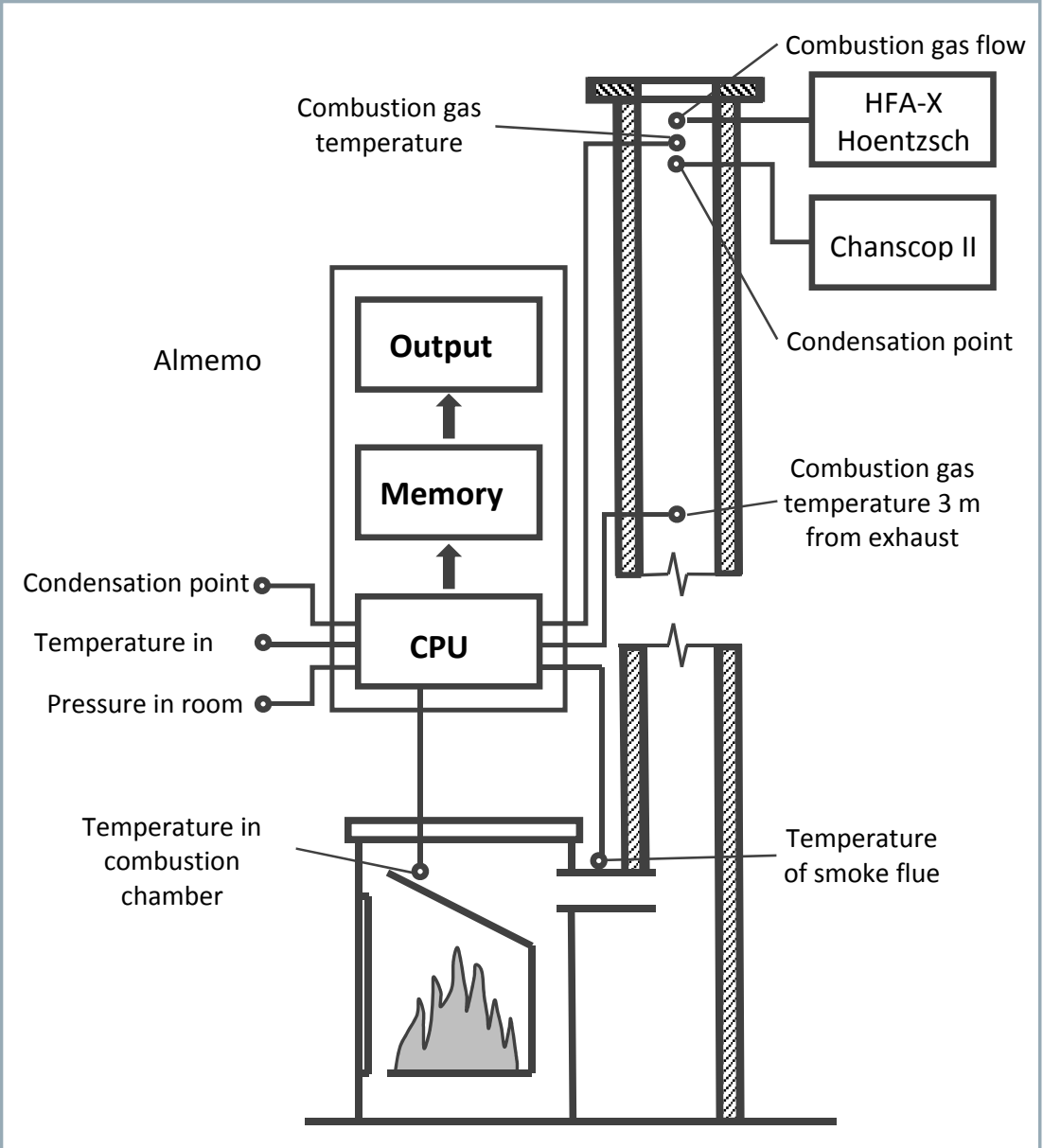

Figure 1 Scheme of measurement

\section{Measurement of temperature of dew point}

The measurement of dew point temperature is based on the principle of condensation of gases on a chilled mirror. The temperature at which the gases contained incombustion products begin to condensate is the temperature of dew point of combustion products. This process is observed in the eyepiece of the equipment.

The form of condensation depends on the gas composition. In case of hydrocarbon, it is a thin film of rainbow ring or a droplet flowing from thet centre of mirror. In case of condensation of water steam, water droplet is generated and stays in the centre of the mirror. The measurement of dew point of combustion products is performed using CHANSCOP ॥ (AMETEK Process Instruments, USA).

The dew point value of combustion products is measured in the upper part of the chimney. The chimney is heated to operating temperature. Combustion products fed into the meter must be at a temperature above the dew point. Condensed liquids (water, hydrocarbons, glycol) must not be present in the chimney before measurements.

\section{Measurement of flow of combustion products}

The measurement principle is based on the observation of turbine's rotation speed, which rotates due to the influence of power of combustion products on the blades of the turbine. Revolutions are measured by an inductive meter. Turbine blades are interfering with the lines of force of the electric field and voltage induced in the coil is then processed.

The measurement of flow speed and volume flow of combustion products is done using the flow meter HFA-X from Hoentzsch (Hoentzsch $\mathrm{GmbH}$, Germany).

\section{Results and discussion}

Temperature measurement in chimney and heated area

The fire was set at 10 a.m., and the last stoking took place at 12 p.m. Measured values of temperatures are recorded in Figure 2.

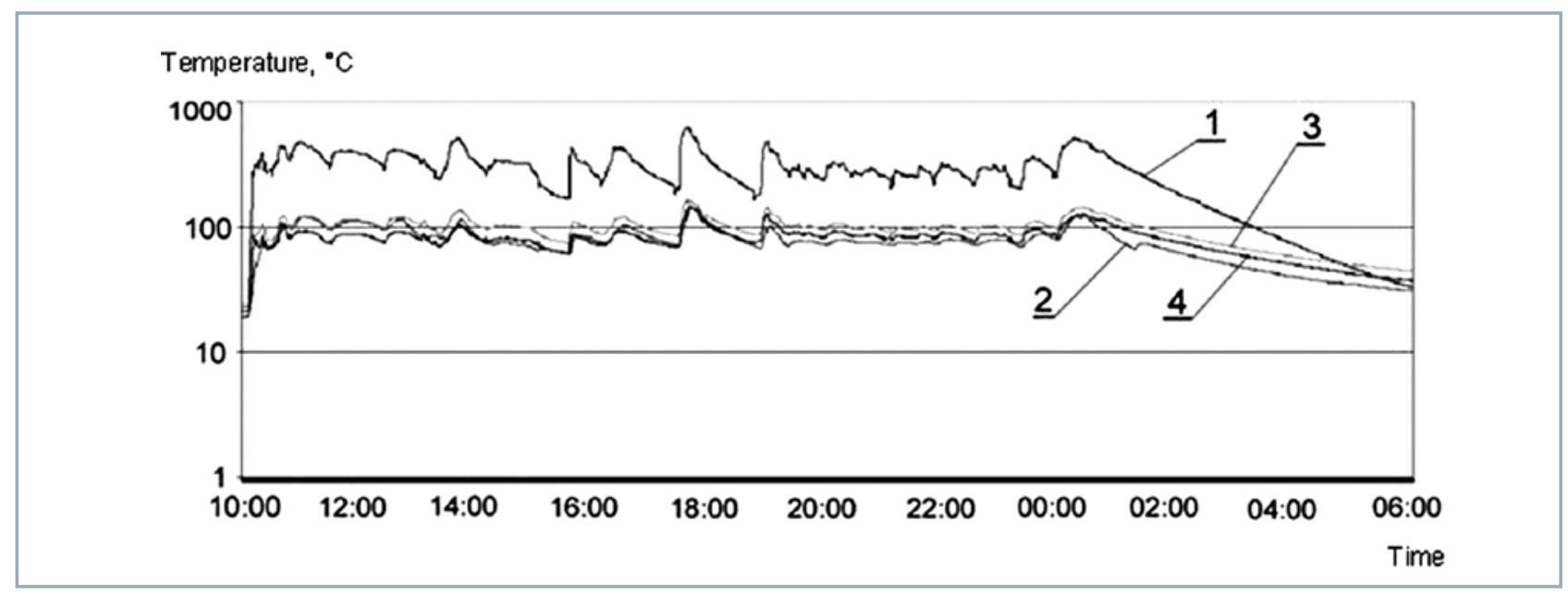

Figure 2 Temperature progress

1 - burning chamber, 2 - chimney up, 3 - chimney, 4 - smoke flew 
Right after setting the fire, increase in temperatures is observed, followed by an almost cyclic substitution of temperatures. Peaks of diagrams show responses to various activities, e.g. stoking or opening of air supply. About 1.5 hours after the last firing, there is a gradual weakening of the fireplace. Decreasing of temperature in both the burning chamber and the room is almost linear.

Temperature curves after setting the fire are shown in Figure 3. The fire was set with air supply being open. The opening of air supply is recorded in black. Room temperature was rising only slightly because in this phase heat is accumulated in the fireplace and heat dissipation takes place, caused by more prominent chimney draught. Temperature in the burning chamber and chimney was rising rapidly. Temperature stabilisation occurs only later.

Repeated stoking of the fire with air intake open causes an increase in temperature. The increase in room temperature after stoking and opening of air supply was recorded only in the first stages of measurement. Figure 4 shows that after heating of the system, the air intake opening has an opposite effect on the growth in room temperature, as significant portion of heat escapes through the chimney.

Heat removal from the fireplace flue duct was ensured by using the fan to generate air flow. This can be seen in Figure 4. Heat transfer from the flue duct results in an increase in room temperature and slight drop in combustion product temperature. The decrease in temperature is not critical. The impact of air inlet opening during fan operation is also visible. Temperature increased in the combustion chamber, flue duct and chimney. On the other hand, room temperature decreased. This can be considered heat wasting.

\section{Measurement of velocity and amount of combustion products}

Measurements of the velocity and amount of combustion products were done by a probe with contactless speed sensor. The probe was installed into the upper part of the chimney, about $1 \mathrm{~m}$ from the top. The actual measurement was carried out during regular operation of the fireplace. Combustion was reduced, with an open secondary air inlet in the fireplace and the primary air inlet closed, with gasification of fuel taking place. Measurements were done 15 times during a three-day period. The average observed value of combustion product velocity is $1.6 \mathrm{~m} \mathrm{~s}^{-1}$. The volume flow rate of combustion products is $12 \mathrm{~m}^{3} \mathrm{~h}^{-1}$.

\section{Measuring of combustion products' dew point}

The equipment for establishing of the dew point was installed in the attic area; nitrogen was used as a coolant. An induction pipe was installed into the head of the chimney. The dew point value was established to be below $51{ }^{\circ} \mathrm{C}$. This value is sufficient for utilisation of waste heat. The flue gas dew point value is $51.7^{\circ} \mathrm{C}$ for wood with moisture value of 25\% (Jelínek, 2003).

\section{Combustion products' heat utilisation proposal}

On the grounds of measurement results, it can be stated that the increase in efficiency of the combustion products' heat utilisation can be achieved by several means, i.e.:

- increasing of efficiency of fireplace utilisation by means of using air intake for affecting the wood combustion;

- utilisation of flue duct heat - forced heat emission from the flue duct surface into the room;

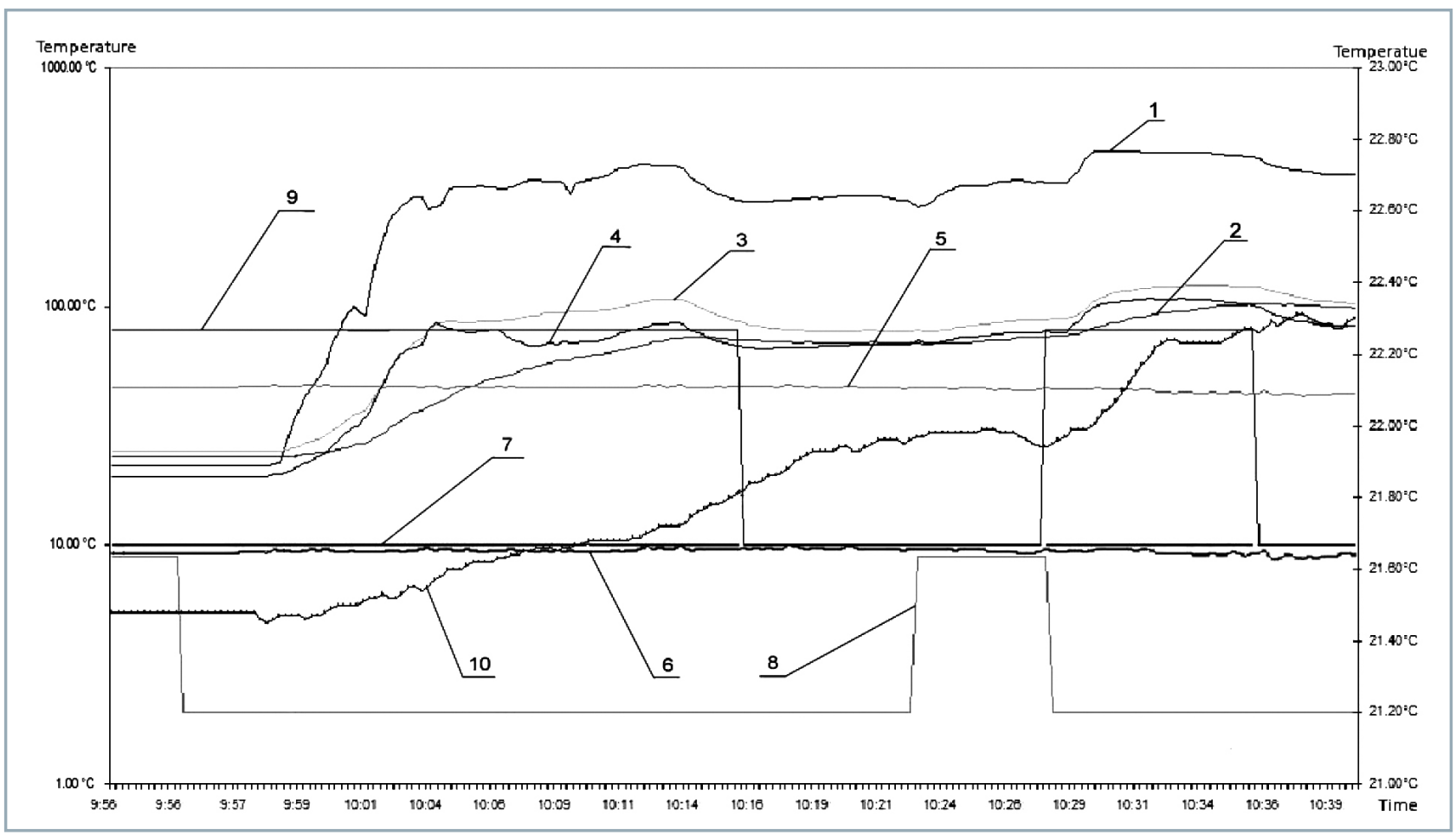

Figure 3 Rise in temperature after setting fire

1 - burning chamber, 2 - chimney up, 3 - chimney, 4 - smoke flew, 5 - humidity, 6 - dew point, 7 - fan, 8 - fuel applying, 9 -air supply, 10 - indoor temperature 


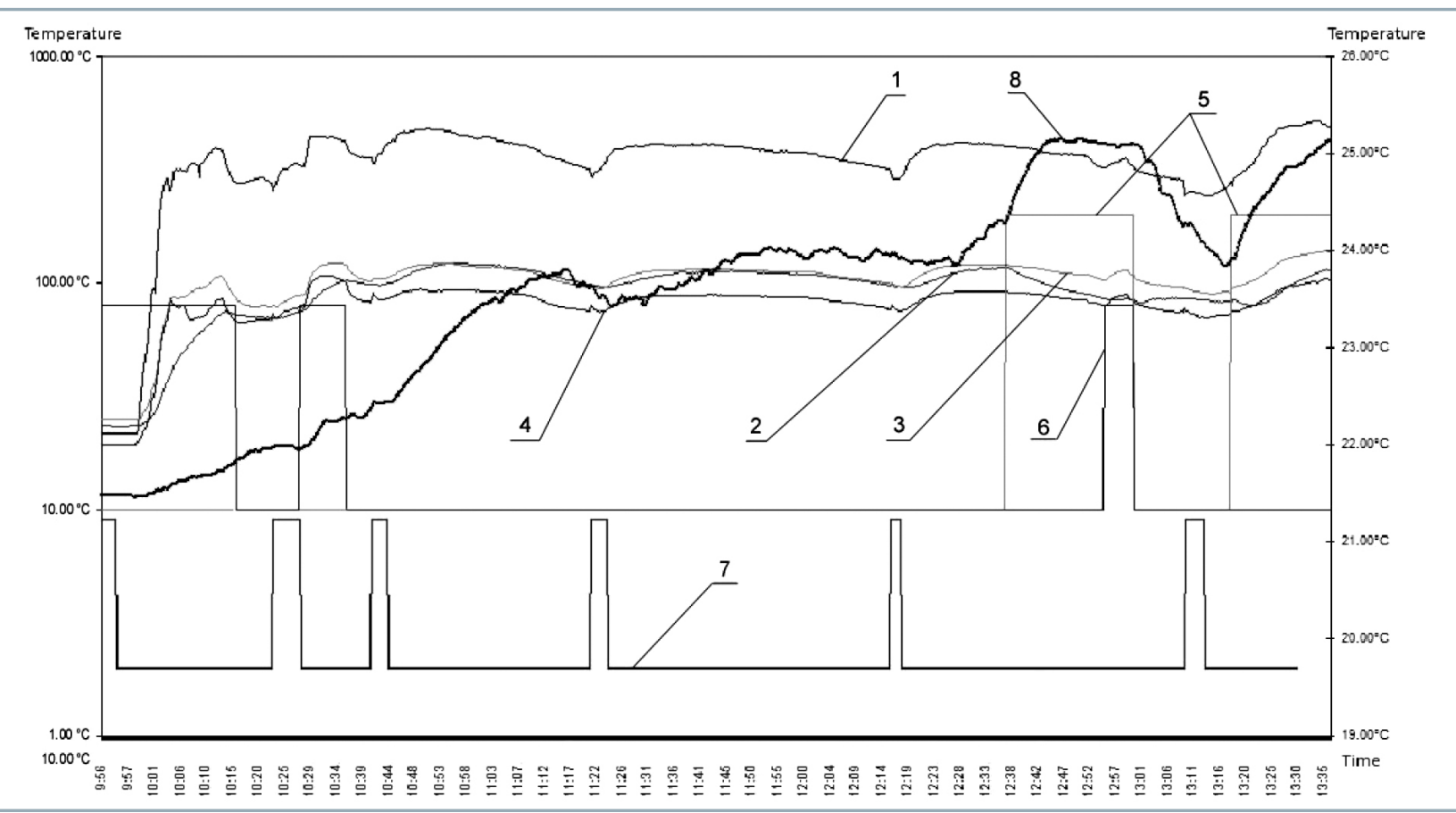

Figure 4 The impact of the opening of air inlet and fan start on internal temperature and combustion product temperature 1 - burning chamber, 2 - chimney up, 3 - chimney, 4 - smoke flew, 5 - fan, 6 - air supply, 7 - fuel applying, 8 - indoor temperature

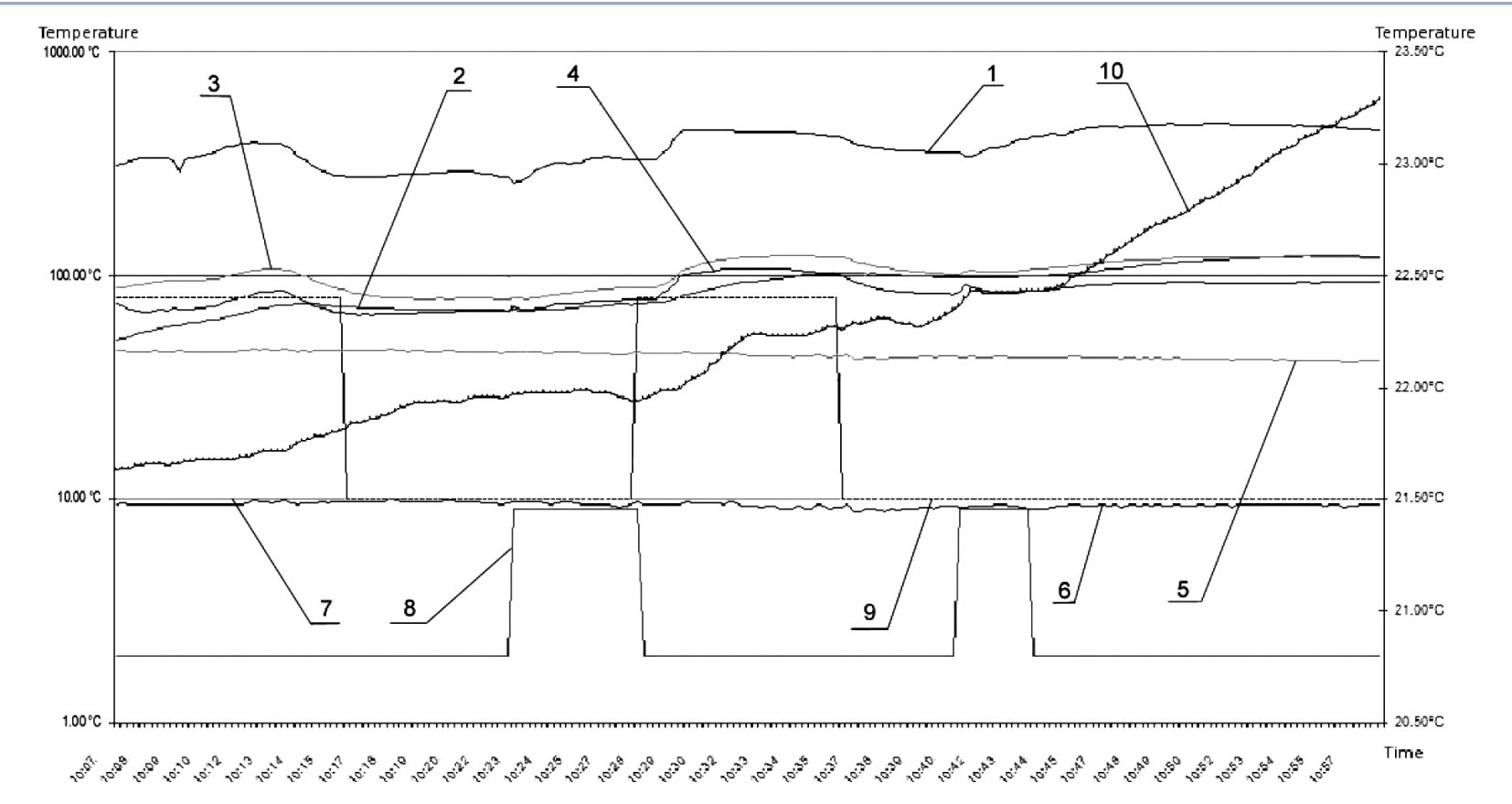

Figure 5 The area of effective behaviour of fireplace

1 - burning chamber, 2 - chimney up, 3 - chimney, 4 - smoke flew, 5 - humidity, 6 - dew point, 7 - fan, 8 - fuel applying, 9 - air supply, 10 - indoor temperature

- utilisation of combustion products' heat, which is the predominant solution for utilisation of heat otherwise escaping into the atmosphere.

Results and analysis of measurements indicate an efficient fireplace utilisation regime, as seen in Figure 5.

Efficient opening and closing regime of the main air intake can be derived from the temperature diagrams. In case of later stoking and closed air intake, combustion by means of gasification took place. This resulted in more efficient use of fuel and increase in time periods necessary between stoking.

Open air intake is needed only for the time required for the start of combustion. Air intake open for longer amount of time is economically disadvantageous.

The utilisation of combustion products' heat can be realised by heat removal by means of forced convection from 


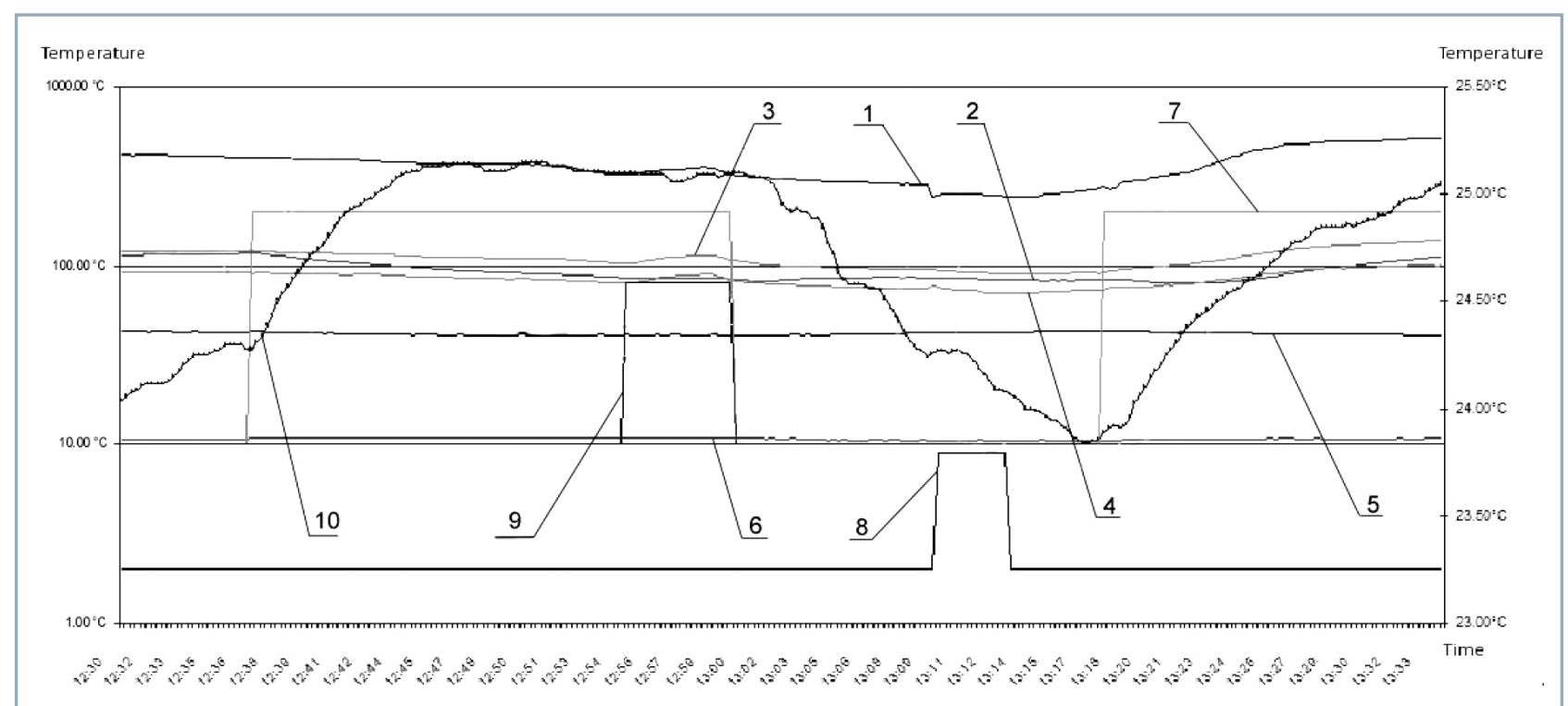

Figure 6 The impact of forced convection on internal temperature

1 - burning chamber, 2 - chimney up, 3 - chimney, 4 - smoke flew, 5 - humidity, 6 - dew point, 7 - fan, 8 - fuel applying, 9 - air supply, 10 - indoor temperature

the chimney (Figure 6). The influence of forced convection on rise of room temperature is visible in the graph, with temperature of combustion products influenced only minimally and natural smoke outlet unhindered.

Results of measurements, i.e. temperatures and dew point of combustion products show that utilisation of such energy is plausible. Values of combustion products' flow through the chimney are necessary for estimating the surface area of the heat exchanger. The exchanger can be of flue gas - air or flue gas - water type. The combustion products' temperature at the upper part of the chimney is $80-120^{\circ} \mathrm{C}$. For heat utilisation, it is necessary to:

- calculate the size of area of the heat exchanger;

- propose the design of the heat exchanger;

- determine the critical values of the accumulation of condensate in the exchanger;

- propose a solution for smoke outlet;

- propose a solution for combustion product flow ventilation (valve);

- propose a solution for air flow regulation on the other side of the exchanger.

The supply of heated combustion products into the heat exchanger can be done by redirecting the combustion products with appropriate temperature into the area of the exchanger. Here, combustion products will flow through the exchanger and transfer the heat to another medium. Combustion products' heat sensor is designed to be installed into the flue tube below the shutter. If combustion products' temperature is not high enough, the combustion products will flow through the original chimney.

It is possible to design the heat exchanger based on calculations using measured data. Flue gas - air exchanger will provide efficient utilisation of the system, can be incorporated into the active ventilation of the building with combustion product recuperation, and fresh heated air will be supplied into the heated area.

For the exchanger solution, it is necessary to determine the temperature of the medium on the secondary side of the exchanger. This is necessary to manage the speed of flow of the secondary medium in the exchanger. The speed is set by a pump in case of water and a fan in case of air. Operating speed should be controlled by an appropriate algorithm in order to achieve the highest possible efficiency.

\section{Conclusion}

Determined temperature values in the chimney suggest that the combustion products' temperature is sufficient for transmission of heat through the surface of flue gas - air heat exchanger. The results of measurements suggest the possibility of such a solution. The analysis of the results led to gathering information usable in practice, such as behaviour of wood combustion, utilisation of flue duct radiation, etc. The system can be further improved by using automatised technology for its control, using appropriate algorithm, and thus optimising the utilisation of combustion products. Such a solution is intended for small thermal systems, such as a single-family house, though its application in industrial operations producing wood-based waste is also possible. In current energetic situation, such solutions are highly topical. Proposed solution can be incorporated into pre-existing structure, though its incorporation during the construction is more economically and technologically suitable.

\section{References}

DUFKA, J. 1997. Vytápení domů a bytů. Praha : Grada Publishing, 1997.

JANÍČEK, F. a i. 2007. Obnovitel'né zdroje energie 1. Bratislava : FEI STU, 2007.

JELÍNEK, V. 2003. Zásady spalování paliv a vznik kondenzace. In Topenáŕství instalace, 2003, č. 1, s. 22-26.

VITÁZEK, I. - KLÚČIK, J. - PINTER, T. - MIKULOVÁ, Z. 2014. Gas emissions in combustion of biofuel. In Acta Technologica Agriculturae, vol. 17, 2014, no. 3, pp. 75-79. ISSN 1335-2555. 